\title{
Energy consumption, economic growth, foreign direct investment and globalization causality nexus in OECD countries:
}

\section{A symbolic transfer entropy analysis}

\author{
Ahdi Noomen Ajmi1 ${ }^{1 *} \cdot$ Seyi Saint Akadiri² \\ ${ }^{1}$ Department of Business Administration, College of Science and Humanities in Slayel, Prince Sattam bin \\ Abdulaziz University, KSA \\ ${ }^{2}$ Central Bank of Nigeria, Nigeria
}

Received: 1 September 2020

Revised: 3 June 2021

Accepted: 9 September 2021

\begin{abstract}
In this paper, we investigate the validity and usefulness of the symbolic transfer entropy (STE) test for longitudinal data by examining causality relationships among foreign direct investment, energy consumption, globalization and economic growth respectively, between the periods 1970-2015 using Organization for Economic Co-operation and Development (OECD) countries as a case study. Our empirical results are in line with the existing literature and empirical outcomes generated using other forms of causality approaches. Thus, we are of the opinion that the STE causality approach is suitable approach for longitudinal panel data.
\end{abstract}

Keywords: Symbolic Transfer Entropy; Panel data; Causality; OECD Countries JEL Classification Codes: C01, C33

\section{Introduction}

To justify the strength and validity of the symbolic transfer entropy test for longitudinal data, and how the results can outperform, corroborate or contrast existing studies results (see Abdouli \& Hammami, 2017; Akadiri, Bekun, Taheri \& Akadiri, 2019; Balibey, 2015; Latif, Latif, Ximei, Pathan, Salam \& Jianqiu, 2018; Leitao, 2015; Ozcan \& Ozturk, 2019; Pao \& Tsai, 2011; Salahuddin, Alam, Ozturk \& Sohag, 2018; Shahbaz, Shahzad, Mahalik \& Sadorsky, 2018; Sarkodie \& Strezov, 2019) basically generated using other forms of causality test, we empirically examine panel-based causality relationships among foreign direct investment, energy consumption, globalization and economic growth respectively, between the periods 1970-2015 using Organization for Economic Co-operation and Development (OECD) countries as a case study. The main objective of this study is to test the significance of symbolic transfer entropy (STE) in practice, and to test whether the causality test results generated are in line with the existing literature and empirical outcomes (as robustness check) from other forms of causality approaches.

\footnotetext{
* Corresponding author. E-mail: ajmi.ahdi.noomen@gmail.com.

Citation: Ajmi, A. N., and Akadiri, S. S. (2021) Energy consumption, economic growth, foreign direct investment and globalization causality nexus in OECD countries: A symbolic transfer entropy analysis, Economics and Business Letters, 10(4), 408-415.
}

DOI: 10.17811/ebl.10.4.2021.408-415 
Contemporary empirical study in the area of Granger causality examination have broaden the causality investigation among macroeconomic variables to the scope of testing longitudinal data via imposition of coefficient restrictions that can be examined using relatively conventional causality approaches most especially when linear relationship are present in panel data. HoltzEakin, Newey and Rosen (1988) that controls for individual fixed effects in panel data and Dumitrescu and Hurlin (2012) that control for heterogeneity in panel model are two major thoughts that adhere to this causality technique. Having consider the lucidity and intelligibility of these conventional causality techniques, the power and sample size problems of these causality tests can gravely worsen or degenerate when the following happen; the linearity proposition fail to hold, presence of regime switching or structural breaks are present in some of the cross-sectional units, or existence of heterogeneity in the data-generating process is across the cross-section units. Furthermore, most of the conventional causality techniques are not built to capture qualitative time-series data.

To overcome this drawback, Camacho et al. (2020) introduced a non-parametric Granger causality test procedure for panel data based on the concept of transfer entropy and a multipleunit symbolic dynamics. In other words, the Camacho et al. (2020) test avoids the need to rely on a linear parametric representation of the data set. Consequently, the test displays correct size and higher power in those cases where causality tests based in linear panel data specifications fail. The symbolic transfer entropy is a non-parametric test, which by construction is built on sensitive propositions. The non-parametric behavior of the symbolic transfer entropy is captured in the Monte-Carlo estimations, proposing that the symbolic transfer entropy exhibit higher power and correct sample size in situations where causality estimations built on linear specifications fails. Thus, symbolic transfer entropy avoids depending on linear parametric representation of the panel dataset, in case the panel model is not consistently estimated or misspecified, which might lead to spurious outcomes or invalidate such empirical results that are majorly built or relies on linear panel data representation ${ }^{1}$. Lastly, the symbolic transfer entropy is built for longitudinal data and it provides robust results even when the data-generating process varies significantly across the cross-section units (Camacho et al., 2020).

The remaining sections of the study are outlined as follow; section 2 discusses data and methodology adopted. Section 3 entails results and empirical findings, while section 4 conclude the study.

\section{Data and methodology}

\subsection{Data}

To conduct our empirical analysis and investigate the relationship between the energy consumption (EC), economic growth (GDP), foreign direct investment (FDI) and globalization (Gb) in OECD countries between the periods 1970-2015, we use the following proxies to measure the variables: energy consumption is measured by the energy use (kg of oil equivalent per capita); economic growth is measured as GDP per capita (constant 2010 US\$); FDI as net inflows (\% of GDP); and the globalization index which measures the economic, social and political dimensions of globalization. All variables are derived from the World Bank, excepting globalization index, which is sourced from the work of Dreher (2006).

\subsection{Methodology}

To investigate the relationship between the energy consumption, economic growth, foreign direct investment and globalization in OECD countries, we use the new non-parametric Granger causality test recently introduced by Camacho et al. (2020). In fact, testing if the values of $x$ with $r$ delays help to predict the actual values of $y$ or testing if the values of $y$ with $r$ delays help to predict the actual values of $x$ necessitates a using of stacked vectors such as:

\footnotetext{
${ }^{1}$ For brevity and the research note word counts, we could not discuss each section in details. Interested reader should see Camacho et al. (2020).
} 


$$
\begin{gathered}
\left\{y_{t}=y_{1, r}, \ldots, y_{1, T_{i}}, \ldots, y_{N, r}, \ldots, y_{N, T_{i}}\right\}, \\
\left\{x_{t}=x_{1, r}, \ldots, x_{1, T_{i}}, \ldots, x_{N, r}, \ldots, x_{N, T_{i}}\right\}, \\
\left\{y_{t-r}=y_{1,1}, \ldots, y_{1, T_{i}-r}, \ldots, y_{N, 1}, \ldots, y_{N, T_{i}-r}\right\}, \\
\left\{x_{t-r}=x_{1,1}, \ldots, x_{1, T_{i}-r}, \ldots, x_{N, 1}, \ldots, x_{N, T_{i}-r}\right\} .
\end{gathered}
$$

Indeed, Camacho et al. (2020) investigate the informational content of the pooled symbols of $\left\{x_{t-r}\right\}$ on the pooled conditional entropy $h_{m}\left(y_{t} \mid y_{t-r}, x_{t-r}\right)$ which is defined as the sum of the conditional entropies of the $N$ cross-sections:

$$
h_{m}\left(y_{t} \mid y_{t-r}, x_{t-r}\right)=\sum_{i=1}^{N} h_{m}\left(y_{i, t} \mid y_{i, t-r}, x_{i, t-r}\right)
$$

Following Schreiber (2000), Camacho et al. (2020) introduced the Symbolic Transfer Entropy (STE) to measure the information transfer from $\left\{x_{t-r}\right\}$ to $\left\{y_{t}\right\}$ given $\left\{y_{t-r}\right\}$

$$
S T E_{x \rightarrow y}(m, r)=h_{m}\left(y_{t} \mid y_{t-r}\right)-h_{m}\left(y_{t} \mid y_{t-r}, x_{t-r}\right)
$$

If the $S T E_{x \rightarrow y}(m, r)$ is large then the past values of $x$ helps to predict current values of $y$. To derive the asymptotic distribution of the statistic $S T E_{x \rightarrow y}(m, r)$, Camacho et al. (2020) propose a bootstrap test procedure which on replicating $B$ times the following steps:

- Step 1: Based on the original pooled time series $\left\{x_{t}\right\}$ and $\left\{y_{t}\right\}$, we start by computing the value of $S T E_{x \rightarrow y}(m, r)$.

- Step 2: Using the stationary bootstrap method of Politis and White (2004), we sample $\left\{x_{i, t}^{b}\right\}$ and $\left\{y_{i, t}^{b}\right\}$ for $i=1,2, \ldots, N$ to compute the relative frequencies of the symbols and obtain the entropy measures $h_{m}^{b}\left(y_{t} \mid y_{t-r}\right)$ and $h_{m}^{b}\left(y_{t} \mid y_{t-r}, x_{t-r}\right)$.

- Step 3: The bootstrapped realization of the symbolic transfer entropy is calculated as:

$$
\operatorname{STE}_{x \rightarrow y}^{b}(m, r)=h_{m}^{b}\left(y_{t} \mid y_{t-r}\right)-h_{m}^{b}\left(y_{t} \mid y_{t-r}, x_{t-r}\right)
$$

- Step 4: We obtain $B$ bootstrap realizations of the statistic $\left\{S T E_{x \rightarrow y}^{b}(m, r)\right\}_{b=1}^{B}$ by repeating $(B-1)$ times the steps 2 and 3 .

- Step 5: The bootstrap $p_{b}$-value is calculated as:

$$
p_{b}=\frac{1}{B} \sum_{b=1}^{B} I\left(S T E_{x \rightarrow y}^{b}(m, r)>S T E_{x \rightarrow y}(m, r)\right),
$$

where $I($.$) is an indicator function which takes 1$ for a true statement and 0 otherwise. If $p_{b}<\alpha$, we reject the null hypothesis that $x$ does not cause $y$ with $\alpha$ is the nominal level.

\section{Empirical results}

To check the integration order of each variable, we implement three panel unit root tests namely the Im, Pesaran and Shin (IPS) test, the ADF - Fisher Chi-square test and the PP - Fisher Chisquare test. The results of panel unit root tests are reported in Table 1. The test statistics show that the economic growth and globalization variables are stationary in the countries but at different levels. However, the energy consumption and FDI are stationary in level. Consequently, the energy consumption and globalization are used in first difference to deal with unit root issues.

Now, we proceed to the next stage, which consists on testing the presence causality between variables based on the Symbolic Transfer Entropy (STE) causality test. Table 2 shows the results of STE causality test. Following Camacho et al. (2020), each panel corresponds to a different lag length specification running from one to three years. The entropy test results reported bidirectional causality between energy consumption and economic growth, between energy consumption and globalization, and between energy growth and FDI. Also, the p-values 
Table 1. Panel unit root tests results.

\begin{tabular}{|c|c|c|c|c|}
\hline Variables & $\begin{array}{ll}\text { Level Intercept } & \\
& \text { Int }\end{array}$ & $\begin{array}{r}\text { Intercept and } \\
\text { trend }\end{array}$ & $\begin{array}{r}\text { First difference } \\
\text { Intercept }\end{array}$ & $\begin{array}{r}\text { Intercept and } \\
\text { trend } \\
\end{array}$ \\
\hline \multicolumn{5}{|c|}{ Im, Pesaran and Shin (IPS) } \\
\hline$E C$ & $0.0012^{\mathrm{a}}$ & 0.9184 & - & $0.0000^{\mathrm{a}}$ \\
\hline$G D P$ & 0.9999 & 0.8657 & $0.0000^{\mathrm{a}}$ & $0.0000^{\mathrm{a}}$ \\
\hline FDI & $0.0000^{\mathrm{a}}$ & $0.0000^{\mathrm{a}}$ & - & - \\
\hline$G B$ & 0.9500 & 0.9984 & $0.0000^{\mathrm{a}}$ & $0.0000^{\mathrm{a}}$ \\
\hline \multicolumn{5}{|c|}{ ADF - Fisher Chi-square } \\
\hline$E C$ & $0.0000^{\mathrm{a}}$ & $0.0255^{\mathrm{b}}$ & - & - \\
\hline$G D P$ & 0.9999 & 0.6900 & $0.0000^{\mathrm{a}}$ & $0.0000^{\mathrm{a}}$ \\
\hline FDI & $0.0000^{\mathrm{a}}$ & $0.0000^{\mathrm{a}}$ & - & - \\
\hline$G B$ & 0.4688 & 0.9985 & $0.0000^{\mathrm{a}}$ & $0.0000^{\mathrm{a}}$ \\
\hline \multicolumn{5}{|c|}{$\overline{P P P}$ - Fisher Chi-square } \\
\hline$E C$ & $0.0117^{\mathrm{b}}$ & $0.0001^{\mathrm{a}}$ & - & - \\
\hline$G D P$ & 0.9999 & 0.9929 & $0.0000^{\mathrm{a}}$ & $0.0000^{\mathrm{a}}$ \\
\hline$F D I$ & $0.0000^{\mathrm{a}}$ & $0.0000^{\mathrm{a}}$ & - & - \\
\hline$G B$ & $0.0007^{\mathrm{a}}$ & 0.9854 & - & $0.0000^{\mathrm{a}}$ \\
\hline
\end{tabular}

Note: Statistical significance at the $5 \%$ and $1 \%$ levels are denoted by the superscripts ${ }^{\mathrm{b}}$ and ${ }^{\mathrm{a}}$, respectively.

of STE show one-way causality running from energy consumption to FDI and from globalization to economic growth. Also, we accept the null hypothesis of non - causality between FDI and globalization who validated the absence globalization-led-FDI hypothesis.

In other word, the results identified that increase in energy consumption increases economic growth and globalization in OECD countries and vice versa. Also, an increase in FDI provides the increase of economic growth and vice versa. Likewise, the results identified that increase in globalization increases economic growth and that increase in energy consumption increases the FDI.

Also, we report in Table 2 the statistical significance of the Net Transfer Entropy (NTE), which is based on one and two tailed p-values. Looking to the p-values of the null symmetric information flow, we report that the net transfer is not significant for all pairwise causality, excepting the case between economic growth and globalization. In fact, the negative value of this net effect implies the prevalence of economic growth over globalization.

Table 2. The Symbolic Transfer Entropy (STE) causality test results.

\begin{tabular}{|c|c|c|c|c|c|c|c|}
\hline \multirow[b]{2}{*}{ Direction } & \multicolumn{3}{|c|}{ EC vs. GDP } & \multirow[b]{2}{*}{ Direction } & \multicolumn{3}{|c|}{ EC vs. FDI } \\
\hline & Stat & 1-tail pval & 2-tail pval & & Stat & 1-tail pval & 2-tail pval \\
\hline \multicolumn{8}{|c|}{ Panel A: $r=1$} \\
\hline$E C \rightarrow G D P$ & 0.026 & 0.150 & & $E C \rightarrow F D I$ & 0.029 & 0.135 & \\
\hline$G D P \rightarrow E C$ & $0.028^{*}$ & 0.085 & & $F D I \rightarrow E C$ & 0.026 & 0.300 & \\
\hline $\begin{array}{c}N e t(E C- \\
G D P)\end{array}$ & -0.002 & 0.325 & 0.670 & $\begin{array}{c}\text { Net }(E C- \\
F D I)\end{array}$ & 0.003 & 0.325 & 0.655 \\
\hline \multicolumn{8}{|c|}{ Panel A: $r=2$} \\
\hline$E C \rightarrow G D P$ & $0.077^{*}$ & 0.015 & & $E C \rightarrow F D I$ & 0.068 & 0.215 & \\
\hline$G D P \rightarrow E C$ & $0.074^{* *}$ & 0.040 & & $F D I \rightarrow E C$ & 0.066 & 0.345 & \\
\hline $\begin{array}{c}N e t(E C- \\
G D P) \\
\end{array}$ & 0.003 & 0.410 & 0.820 & $\begin{array}{c}N e t(E C- \\
F D I)\end{array}$ & 0.002 & 0.430 & 0.885 \\
\hline \multicolumn{8}{|c|}{ Panel A: $r=3$} \\
\hline$E C \rightarrow G D P$ & 0.064 & 0.295 & & $E C \rightarrow F D I$ & $0.074^{*}$ & 0.085 & \\
\hline$G D P \rightarrow E C$ & 0.066 & 0.315 & & $F D I \rightarrow E C$ & 0.064 & 0.490 & \\
\hline $\begin{array}{c}\operatorname{Net}(E C- \\
G D P)\end{array}$ & -0.002 & 0.470 & 0.875 & $\begin{array}{c}\text { Net }(E C- \\
F D I)\end{array}$ & 0.010 & 0.160 & 0.385 \\
\hline
\end{tabular}


Table 2. The Symbolic Transfer Entropy (STE) causality test results (cont'd).

\begin{tabular}{|c|c|c|c|c|c|c|c|}
\hline \multirow{2}{*}{ Direction } & \multicolumn{3}{|c|}{ EC vs. Gb } & \multirow{2}{*}{ Direction } & \multicolumn{3}{|c|}{ GDP vs. FDI } \\
\hline & Stat & 1-tail pval & 2-tail pval & & Stat & 1-tail pval & 2-tail pval \\
\hline \multicolumn{8}{|c|}{ Panel A: $r=1$} \\
\hline$E C \rightarrow G b$ & 0.022 & 0.390 & & $G D P \rightarrow F D I$ & $0.029^{*}$ & 0.065 & \\
\hline$G b \rightarrow E C$ & $0.028^{*}$ & 0.070 & & $F D I \rightarrow G D P$ & $0.039^{*}$ & 0.075 & \\
\hline $\begin{array}{c}N e t(E C- \\
G b)\end{array}$ & -0.005 & 0.180 & 0.360 & $\begin{array}{c}N e t(G D P- \\
F D I)\end{array}$ & 0.000 & 0.495 & 0.955 \\
\hline \multicolumn{8}{|c|}{ Panel A: $r=2$} \\
\hline$E C \rightarrow G b$ & 0.065 & 0.190 & & $G D P \rightarrow F D I$ & 0.064 & 0.325 & \\
\hline$G b \rightarrow E C$ & $0.074^{* *}$ & 0.015 & & $F D I \rightarrow G D P$ & 0.065 & 0.265 & \\
\hline $\begin{array}{c}N e t(E C- \\
G b)\end{array}$ & -0.009 & 0.175 & 0.410 & $\begin{array}{c}N e t(G D P- \\
F D I)\end{array}$ & -0.000 & 0.450 & 0.945 \\
\hline \multicolumn{8}{|c|}{ Panel A: $r=3$} \\
\hline$E C \rightarrow G b$ & $0.070^{*}$ & 0.050 & & $G D P \rightarrow F D I$ & 0.063 & 0.465 & \\
\hline$G b \rightarrow E C$ & $0.074^{* *}$ & 0.020 & & $F D I \rightarrow G D P$ & $0.073^{*}$ & 0.080 & \\
\hline $\begin{array}{c}N e t(E C- \\
G b)\end{array}$ & -0.004 & 0.440 & 0.720 & $\begin{array}{c}\text { Net }(G D P- \\
F D I)\end{array}$ & -0.009 & 0.185 & 0.360 \\
\hline
\end{tabular}

For robustness, we add the results of the Holtz-Eakin, Newey, and Rosen (1988, HNR) and the Dumitrescu and Hurlin (2012, DH) causality tests in Table 3. In addition, Table 4 reports a comparison between the causality results of the Symbolic Transfer Entropy causality test with the HNR and the DH causality tests. We show that the HNR provide one-way causality running FDI to energy consumption when the DH and STE causality tests confirm the existence of causality in the opposite direction. The roles of energy consumption in influencing the level of FDI inflows have been extensively discussed in literature. To some economists, FDI causes energy consumption, while to some; energy consumption causes FDI either in a negative or positive way. Increase in FDI would increase energy consumption and vice versa. This finding is in line with the study of (Omri \& Kahouli, 2014; Kivyiro \& Arminen, 2014) that increase in energy consumption would likely increases FDI, and vice versa, while we could not reject the null hypothesis of non-causal relationship between FDI and economic growth, and FDI and globalization respectively.

Table 2. The Symbolic Transfer Entropy (STE) causality test results (cont'd).

\begin{tabular}{|c|c|c|c|c|c|c|c|}
\hline & & GDP vs. Gb & & & & FDI vs. Gb & \\
\hline Direction & Stat & 1-tail pval & 2-tail pva & Direction & Stat & 1-tail pval & 2-tail pval \\
\hline \multicolumn{8}{|c|}{ Panel A: $r=1$} \\
\hline$G D P \rightarrow G b$ & 0.023 & 0.480 & & $F D I \rightarrow G b$ & 0.018 & 0.905 & \\
\hline$G b \rightarrow G D P$ & $0.035^{* * *}$ & 0.000 & \multirow[b]{2}{*}{0.055} & $G b \rightarrow F D I$ & 0.020 & 0.810 & \\
\hline $\begin{array}{c}\text { Net }(G D P- \\
G b) \\
\end{array}$ & -0.013 & 0.015 & & $\begin{array}{c}\text { Net }(F D I- \\
G b) \\
\end{array}$ & -0.002 & 0.445 & 0.775 \\
\hline \multicolumn{8}{|c|}{ Panel A: $r=2$} \\
\hline$G D P \rightarrow G b$ & 0.058 & 0.610 & & $F D I \rightarrow G b$ & 0.067 & 0.190 & \\
\hline$G b \rightarrow G D P$ & $0.080^{* * * *}$ & 0.005 & \multirow[b]{2}{*}{0.050} & $G b \rightarrow F D I$ & 0.056 & 0.700 & \\
\hline $\begin{array}{c}\text { Net }(G D P- \\
G b)\end{array}$ & -0.022 & 0.025 & & $\begin{array}{c}N e t(F D I- \\
G b)\end{array}$ & 0.011 & 0.150 & 0.285 \\
\hline \multicolumn{8}{|c|}{ Panel A: $r=3$} \\
\hline$G D P \rightarrow G b$ & 0.069 & 0.145 & & $F D I \rightarrow G b$ & 0.073 & 0.110 & \\
\hline$G b \rightarrow G D P$ & $0.082^{* * * *}$ & 0.005 & & $G b \rightarrow F D I$ & 0.066 & 0.300 & \\
\hline $\begin{array}{c}\text { Net }(G D P- \\
G b)\end{array}$ & -0.013 & 0.135 & 0.260 & $\begin{array}{c}\text { Net }(F D I- \\
G b)\end{array}$ & 0.007 & 0.240 & 0.505 \\
\hline
\end{tabular}

Note: $* * *, * *$ and $*$ represent significance level at $0.0,0.051$ and 0.10 per cents. 
Table 3. HNR and DH causality tests results.

\begin{tabular}{|c|c|c|c|c|c|c|c|c|c|}
\hline \multirow[b]{3}{*}{ Direction } & \multicolumn{4}{|c|}{ EC vs. GDP } & \multirow[b]{3}{*}{ Direction } & \multicolumn{4}{|c|}{ EC vs. FDI } \\
\hline & \multicolumn{2}{|c|}{ HNR } & \multicolumn{2}{|c|}{ DH } & & \multicolumn{2}{|c|}{ HNR } & \multicolumn{2}{|c|}{ DH } \\
\hline & Stat & p-value & Stat & p-value & & Stat & p-value & Stat & p-value \\
\hline \multicolumn{10}{|c|}{ Panel A: $r=1$} \\
\hline$E C \rightarrow G D P$ & $-9.643^{* * * *}$ & 0.000 & 1.795 & 0.135 & $E C \rightarrow F D I$ & 0.440 & 0.660 & $13.115^{\text {*** }}$ & 0.000 \\
\hline$G D P \rightarrow E C$ & $-1.773^{*}$ & 0.076 & $6.630^{* * * *}$ & 0.000 & $F D I \rightarrow E C$ & $-2.663^{* * * *}$ & 0.008 & 2.542 & 0.105 \\
\hline \multicolumn{10}{|c|}{ Panel A: $r=2$} \\
\hline$E C \rightarrow G D P$ & $-5.995^{* * *}$ & 0.000 & $6.161^{* * *}$ & 0.005 & $E C \rightarrow F D I$ & -0.868 & 0.386 & $21.395^{* * *}$ & 0.000 \\
\hline$G D P \rightarrow E C$ & -1.198 & 0.231 & 9.037 & 0.000 & $F D I \rightarrow E C$ & $2.945^{* * *}$ & 0.003 & 5.000 & 0.110 \\
\hline \multicolumn{10}{|c|}{ Panel A: $r=3$} \\
\hline$E C \rightarrow G D P$ & 0.147 & 0.883 & $4.263^{*}$ & 0.065 & $E C \rightarrow F D I$ & 0.220 & 0.826 & $29.694^{* * *}$ & 0.000 \\
\hline$G D P \rightarrow E C$ & 0.957 & 0.338 & $8.379^{* * * *}$ & 0.000 & $F D I \rightarrow E C$ & $-1.691^{*}$ & 0.091 & 6.393 & 0.115 \\
\hline
\end{tabular}

Note: HNR and DH represent the Holtz-Eakin, Newey, and Rosen (1988) and the Dumitrescu and Hurlin (2012) causality tests, respectively. $* * * * *$ and $*$ represent significance level at $0.0,0.051$ and 0.10 per cents.

Table 3. HNR and DH causality tests results (cont'd).

\begin{tabular}{|c|c|c|c|c|c|c|c|c|c|}
\hline \multirow[b]{3}{*}{ Direction } & \multicolumn{4}{|c|}{ EC vs. Gb } & \multicolumn{5}{|c|}{ GDP vs. FDI } \\
\hline & \multicolumn{2}{|c|}{ HNR } & \multicolumn{2}{|c|}{ DH } & \multirow[b]{2}{*}{ Direction } & \multicolumn{2}{|c|}{ HNR } & \multicolumn{2}{|c|}{ DH } \\
\hline & Stat & p-value & Stat & p-value & & Stat & p-value & Stat & p-value \\
\hline \multicolumn{10}{|c|}{ Panel A: $r=1$} \\
\hline$E C \rightarrow G b$ & -0.475 & 0.635 & 0.684 & 0.575 & $G D P \rightarrow F D I$ & $-1.817^{*}$ & 0.069 & $3.558^{* *}$ & 0.020 \\
\hline$G b \rightarrow E C$ & 0.770 & 0.441 & 0.925 & 0.350 & $F D I \rightarrow G D P$ & $8.106^{* * * *}$ & 0.000 & $3.513^{* * *}$ & 0.020 \\
\hline \multicolumn{10}{|c|}{ Panel A: $r=2$} \\
\hline$E C \rightarrow G b$ & -0.909 & 0.364 & 1.717 & 0.305 & $G D P \rightarrow F D I$ & 1.590 & 0.112 & 1.189 & 0.505 \\
\hline$G b \rightarrow E C$ & -0.996 & 0.319 & -1.590 & 0.225 & $F D I \rightarrow G D P$ & $-4.687^{* * * *}$ & 0.000 & $7.846^{* * *}$ & 0.000 \\
\hline \multicolumn{10}{|c|}{ Panel A: $r=3$} \\
\hline$E C \rightarrow G b$ & -1.127 & 0.260 & 0.102 & 0.940 & $G D P \rightarrow F D I$ & 1.141 & 0.254 & 1.762 & 0.280 \\
\hline$G b \rightarrow E C$ & 0.771 & 0.441 & -0.432 & 0.765 & $F D I \rightarrow G D P$ & $-7.998^{* * * *}$ & 0.000 & $6.675^{* * * *}$ & 0.005 \\
\hline
\end{tabular}

Note: HNR and DH represent the Holtz-Eakin, Newey, and Rosen (1988) and the Dumitrescu and Hurlin (2012) causality tests, respectively. $* * *, * *$ and $*$ represent significance level at $0.0,0.051$ and 0.10 per cents.

Table 3. HNR and DH causality tests results (cont'd).

\begin{tabular}{|c|c|c|c|c|c|c|c|c|c|}
\hline \multirow[b]{3}{*}{ Direction } & \multicolumn{4}{|c|}{ GDP vs. Gb } & \multirow[b]{3}{*}{ Direction } & \multicolumn{4}{|c|}{ FDI vs. Gb } \\
\hline & \multicolumn{2}{|c|}{ HNR } & \multicolumn{2}{|c|}{ DH } & & \multicolumn{2}{|c|}{ HNR } & \multicolumn{2}{|c|}{ DH } \\
\hline & Stat & p-value & Stat & p-value & & Stat & p-value & Stat & p-value \\
\hline \multicolumn{10}{|c|}{ Panel A: $r=1$} \\
\hline$G D P \rightarrow G b$ & 0.397 & 0.691 & 1.935 & 0.135 & $F D I \rightarrow G b$ & -0.424 & 0.672 & -1.288 & 0.310 \\
\hline$G b \rightarrow G D P$ & $1.692^{*}$ & 0.091 & -0.406 & 0.710 & $G b \rightarrow F D I$ & -0.736 & 0.462 & 1.284 & 0.270 \\
\hline \multicolumn{10}{|c|}{ Panel A: $r=2$} \\
\hline$G D P \rightarrow G b$ & -0.634 & 0.526 & $2.876^{*}$ & 0.050 & $F D I \rightarrow G b$ & 0.720 & 0.472 & 1.292 & 0.295 \\
\hline$G b \rightarrow G D P$ & $-5.380^{* * *}$ & 0.000 & -0.299 & 0.820 & $G b \rightarrow F D I$ & 0.543 & 0.587 & 0.283 & 0.810 \\
\hline \multicolumn{10}{|c|}{ Panel A: $r=3$} \\
\hline$G D P \rightarrow G b$ & 0.370 & 0.711 & -0.970 & 0.425 & $F D I \rightarrow G b$ & -0.311 & 0.756 & 0.918 & 0.445 \\
\hline$G b \rightarrow G D P$ & 1.010 & 0.312 & -0.645 & 0.560 & $G b \rightarrow F D I$ & -0.445 & 0.656 & 0.099 & 0.940 \\
\hline
\end{tabular}

Note: HNR and DH represent the Holtz-Eakin, Newey, and Rosen (1988) and the Dumitrescu and Hurlin (2012) causality tests, respectively. ${ }^{* * *}, *$ represent significance level at 0.01 and 0.10 per cents.

Also, HNR and DH report the absence of causality between energy consumption and globalization when STE show bidirectional causality. The roles of globalization in influencing energy consumption have been reported in literature. Globalization, either politically, economically or socially causes energy consumption in a negative or positive way and vice versa. This finding is in line with the study of (Saint Akadiri et al, 2019, 2020; Shahbaz et al, 
2018) that increase/decrease in globalization would likely increases energy consumption, and vice versa. The bidirectional causality relationship reported by STE tests lends support from the study of Saint Akadiri et al $(2019 ; 2020)$. Thus we are of the opinion that STE causality test results resonate existing findings (Saint Akadiri \& Ajmi, 2020). Finally, DH reports unidirectional causality running from economic growth to globalization. However, STE and HNR causality tests show unidirectional causality running from globalization to economic growth. This result resonate the study of Shahbaz et al (2018) and Saint Akadiri et al (2019; 2020) respectively.

Table 4. Summary of causality results.

\begin{tabular}{cccc}
\hline \hline Direction & HNR & DH & STE \\
\hline$E C$ vs. $G D P$ & $\mathrm{~B}$ & $\mathrm{~B}$ & $\mathrm{~B}$ \\
$E C$ ss. $F D I$ & $\mathrm{FDI} \rightarrow \mathrm{EC}$ & $\mathrm{EC} \rightarrow$ FDI & $\mathrm{EC} \rightarrow$ FDI \\
$E C$ s. $G b$ & $\mathrm{NC}$ & $\mathrm{NC}$ & $\mathrm{B}$ \\
$G D P$ s. $F D I$ & $\mathrm{~B}$ & $\mathrm{~B}$ & $\mathrm{~B}$ \\
$G D P$ vs. $G b$ & $\mathrm{~Gb} \rightarrow \mathrm{GDP}$ & $\mathrm{GDP} \rightarrow \mathrm{Gb}$ & $\mathrm{Gb} \rightarrow \mathrm{GDP}$ \\
$F D I v s . G b$ & $\mathrm{NC}$ & $\mathrm{NC}$ & $\mathrm{NC}$ \\
\hline \hline
\end{tabular}

Note: $\mathrm{B}, \mathrm{X} \rightarrow \mathrm{Y}$ and $\mathrm{NC}$ denote bidirectional causality, causality running from $\mathrm{X}$ to $\mathrm{Y}$ and no causality between variables, respectively.

\section{Concluding remarks}

To substantiate the validity and usefulness of the symbolic transfer entropy test for longitudinal data, and whether the results outperform, validate or contrast other existing studies results, this study investigate the relationship between energy consumption, economic growth, FDI and globalization for OECD countries we used annual data covering the period $1972-2015$. For comparison, we employ also two conventional causality approaches: the Holtz-Eakin, Newey and Rosen (1988) that controls for individual fixed effects in panel data and the Dumitrescu and Hurlin (2012) that control for heterogeneity in panel model.

Based on empirical results, it would be right to conclude that STE tests for longitudinal data conforms with the existing results using conventional causality techniques, thus we are of the opinion that STE causality test results resonate existing findings, and it is suitable causality approach for longitudinal data (see Saint Akadiri \& Ajmi, 2020) and causality tests for OECD countries.

\section{References}

Abdouli, M., and Hammami, S. (2017) Investigating the causality links between environmental quality, foreign direct investment and economic growth in MENA countries, International Business Review, 26(2), 264-278.

Akadiri, S. S., Bekun, F. V., Taheri, E., and Akadiri, A. C. (2019) Carbon emissions, energy consumption and economic growth: a causality evidence, International Journal of Energy Technology and Policy, 15(2-3), 320-336.

Balibey, M. (2015) Relationships among CO2 emissions, economic growth and foreign direct investment and the EKC hypothesis in Turkey, International Journal of Energy Economics and Policy, 5(4).

Camacho, M., Romeub, A., and Ruiz-Marin, M. (2020) Symbolic transfer entropy test for causality in longitudinal data, Economic Modelling (In press).

Dreher, A. (2006). Does globalization affect growth? Evidence from a new index of globalization. Applied economics, 38(10), 1091-1110. 
Kivyiro, P., and Arminen, H. (2014) Carbon dioxide emissions, energy consumption, economic growth, and foreign direct investment: Causality analysis for Sub-Saharan Africa, Energy, 74, 595-606.

Latif, Z., Latif, S., Ximei, L., Pathan, Z. H., Salam, S., and Jianqiu, Z. (2018), The dynamics of ICT, foreign direct investment, globalization and economic growth: Panel estimation robust to heterogeneity and cross-sectional dependence, Telematics and Informatics, 35(2), 318328.

Leitão, N. C. (2015) Energy consumption and foreign direct investment: a panel data analysis for Portugal, International Journal of Energy Economics and Policy, 5, 138-147.

Ozcan, B., and Ozturk, I. (2019) Renewable energy consumption-economic growth nexus in emerging countries: A bootstrap panel causality test, Renewable and Sustainable Energy Reviews, 104, 30-37.

Omri, A., and Kahouli, B. (2014) Causal relationships between energy consumption, foreign direct investment and economic growth: Fresh evidence from dynamic simultaneousequations models, Energy Policy, 67, 913-922.

Pao, H. T., and Tsai, C. M. (2011) Multivariate Granger causality between CO2 emissions, energy consumption, FDI and GDP : evidence from a panel of BRIC (Brazil, Russian Federation, India, and China) countries, Energy, 36(1), 685-693.

Politis, D., and White, H. (2004) Automatic block-length selection for the dependent bootstrap, Econometric Reviews, 23, 53-70.

Saint Akadiri, S., \& Ajmi, A. N. (2020). Causality relationship between energy consumption, economic growth, FDI, and globalization in SSA countries: a symbolic transfer entropy analysis. Environmental Science and Pollution Research, 27(35), 44623-44628.

Salahuddin, M., Alam, K., Ozturk, I., and Sohag, K. (2018) The effects of electricity consumption, economic growth, financial development and foreign direct investment on CO2 emissions in Kuwait, Renewable and Sustainable Energy Reviews, 81, 2002-2010.

Shahbaz, M., Shahzad, S. J. H., Mahalik, M. K., and Sadorsky, P. (2018) How strong is the causal relationship between globalization and energy consumption in developed economies? A country-specific time-series and panel analysis, Applied Economics, 50(13), 1479-1494.

Sarkodie, S. A., and Strezov, V. (2019) Effect of foreign direct investments, economic development and energy consumption on greenhouse gas emissions in developing countrie,. Science of the Total Environment, 646, 862-871.

Schreiber, T. (2000). Measuring information transfer, Physical Review Letters, 85, 461-464. 